\title{
Incidence of tibial fracture in child skiers
}

\author{
S.A. Hill, FRCS \\ Department of Orthopaedics, Royal Berkshire Hospital, Reading
}

\begin{abstract}
Skiing is an increasingly popular sport amongst both adults and children. Opportunities for skiing within the United Kingdom are limited, but the introduction of increasing numbers of dry ski slopes has made the sport more available. The nature of injuries sustained by adults on snow and dry slopes is well documented, but this is less true of childhood injury, especially on dry slopes.

A consecutive series of 92 patients with skiing injuries is presented. Both dry slope and snow slope injuries are included. The incidence of tibial fracture in children was ten times that of adults. The nature of all injuries sustained during the study period is documented, the childhood tibial fractures are described in detail, and possible aetiological factors are discussed.
\end{abstract}

Keywords: Children, skiing injury, tibial fracture

\section{Introduction}

Skiing is an increasingly popular sport. It is estimated that up to one million people from the United Kingdom including a large number of children will travel abroad on skiing holidays in 1989 . This popularity has also resulted in a growing number of dry ski slopes nearly one hundred in the UK.

Advances in equipment design and increased awareness have resulted in increased safety, and the number of long bone fractures in adults has reduced. Two studies from the United Kingdom have shown a difference in the nature of injuries sustained on dry slopes, with a predominance of upper limb injuries, compared to snow skiing ${ }^{1,2}$. These studies did not however include children below the age of 13 years.

A preliminary survey of such children presenting to the Royal Berkshire Hospital suggested that younger skiers sustained a higher incidence of long bone fractures than adults on both dry and snow slopes. A three month prospective study was instituted to investigate this impression. The findings demonstrate a disturbingly high incidence of tibial fracture amongst children.

The nature of adult and childhood injuries sustained during the study period is documented, with

Address for correspondence: S.A. Hill, Department of Orthopaedics, Nuffield Orthopaedic Centre, Headington, Oxford particular attention to the cases of childhood tibial fracture.

\section{Methods}

All patients with skiing injuries presenting to the casualty department of the Royal Berkshire Hospital, Reading during the period 1 January 1987 to 31 March 1987 are included. There were 92 patients with 94 injuries. This includes self referred patients from local dry slopes, and follow-up referrals following injury abroad. The age, sex, site of injury, diagnosis, mechanism of injury and whether sustained on dry or snow slopes was recorded.

\section{Results}

The study group represents ten per cent of all sports injuries seen in the casualty department during the study period. Of the 94 injuries, 36 were sustained on dry slopes and 58 on snow. There was an equal distribution amongst male and female patients. Sixteen of the 94 injuries occurred in the under 16 year age group, equally distributed between dry and snow slopes.

The ratio of upper to lower limb injury was dependent on skiing surface with $6: 1$ on dry slopes and $2: 3$ on snow. This confirms the findings of other authors ${ }^{1,2}$. All injuries are recorded in Table 1 . In adults this shows a preponderance of thumb and finger injuries on dry slopes compared to knee ligament injuries on snow.

In children however, three out of eight snow injuries and three out of eight dry slope injuries resulted in tibial fracture. These cases are analysed in more detail. Of the six children with tibial fractures, one was male (aged $11 \mathrm{yr}$ ) and five female (ages 5, 10, 10, 11 and $13 \mathrm{yr})$.

\section{Dry slope injuries}

Case 1: Female 5 yr Undisplaced spiral fracture, middle third of right tibia. Patient fell awkwardly, tripped on edge of matting and fell downwards and forwards. Bindings did not release.

Case 2: Female 10 yr Undisplaced spiral fracture, middle third of left tibia. Fell head over heels after caught ski tip in matting. Bindings failed to release.

Case 3: Female 11 yr Undisplaced spiral fracture, middle third of left tibia. Fell during descent at slow speed. Bindings failed to release. 
Table 1. Summary of injuries sustained

\begin{tabular}{lcccc}
\hline & \multicolumn{2}{c}{ Dry slope } & \multicolumn{2}{c}{ Snow slope } \\
& Adult & Child & Adult & Child \\
\hline Upper limb & 26 & 5 & 22 & $1=54$ \\
Thumb fracture & 12 & 1 & 1 & 0 \\
Thumb sprain & 6 & 2 & 5 & 0 \\
Finger fracture/sprain & 3 & 1 & 1 & 0 \\
Carpal fracture/sprain & 4 & 0 & 3 & 0 \\
Radius fracture & 1 & 0 & 3 & 0 \\
Shoulder/clavicle injury & 0 & 1 & 9 & 1 \\
Lower limb & 2 & 3 & 25 & $7=37$ \\
Hip sprain & 0 & 0 & 1 & 2 \\
Knee ligament injury & 2 & 0 & 17 & 1 \\
Patella fracture & 0 & 0 & 1 & 0 \\
Tibia fracture & 0 & 3 & 3 & 3 \\
Ankle fracture/sprain & 0 & 0 & 3 & 1 \\
Head/Neck/Facial injury & 0 & 0 & 3 & $0=3$ \\
\hline Total & 28 & 8 & 50 & $8=94$ \\
\hline
\end{tabular}

\section{Snow slopes}

Case 4: Male 11 yr Minimally displaced transverse fracture, lower third of right tibia. Attempting to avoid another skier, skis caught in snow, fell forwards. Bindings did not release, having been previously over tightened due to repeated loosening.

Case 5: Female 13 yr Undisplaced spiral fracture, middle third of right tibia. Hit bump in snow causing boot to twist. Binding failed to release.

Case 6: Female 10 yr Undisplaced oblique fracture, lower third of right tibia. Lost control during snowplough turn at low speed, causing forward tilt and twisting to leg. Binding did not release.

\section{Discussion}

The nature of childhood and adult skiing injuries differs. Ungerholm et al. showed a significantly higher incidence of tibial fracture among snow-skiing injuries of the under 16 age group ${ }^{3}$. In the current study, tibial fracture constituted 38 per cent of all childhood injuries on both snow and dry slopes. This represents an almost tenfold greater incidence compared to adults.
The cause of increased tibial fracture in children may lie with equipment design or an intrinsic susceptibility of the child's skeleton to rotatory force. Using cadaver studies, Lange and Asang showed that the breaking strength of the childhood tibia is considerably lower than that of the 20-60 year age group ${ }^{4}$. They showed a direct correlation between age and fracture torsional moment in the 10-16 year age group (force needed increasing with age), while the force remained higher and constant in the 20-60 year group. Thus the force needed to fracture a 10 year old's tibia was approximately half that needed for a 20 year old's tibia.

It is also interesting that in the six cases described, all of which occurred at relatively low velocity, the bindings failed to release on each occasion. This concurs with Ungerholm et al. who reported a high frequency of bindings with too high release force values ${ }^{3}$.

Manufacturers are increasingly aware of the need to provide for the particular requirements of younger skiers. Appropriate boots and bindings are available. Attention should be paid to the careful adjustment of children's bindings as this may reduce the number of tibial fractures both on foreign skiing holidays and on dry slopes within the United Kingdom.

\section{Acknowledgements}

I would like to thank David Hearns of the Ski Club of Great Britain, and Mr O.W. Hart of Salomon Ski Equipment (Great Britain) Ltd for the helpful information provided in response to my enquiries.

\section{References}

1 Caves, P.K. Artificial ski-slope injuries $J R$ Coll Surg Edinb 1969, 14, 340-344

2 Steedman, D.J. Artificial ski slope injuries: a one year prospective study Injury 1986, 17, 208-212

3 Ungerholm, S., Engkvist, O., Gierup, J., Lindsjö, U. and Balkfors, B. Skiing injuries in children and adults: A comparative study from an 8-year period Int J Sports Med $1983,4,236-240$

4 Lange, J. and Asang, E. Comparison of the shinbone loading capacities of children and adults, International Series on Sports Sciences 1978, 5, University Park Press 